\title{
Effect of adaptive learning style scenarios on learning achievements
}

Citation for published version (APA):

Bozhilov, D., Stefanov, K., \& Stoyanov, S. (2009). Effect of adaptive learning style scenarios on learning achievements. International Journal of Continuing Engineering Education and Lifelong Learning (IJCEELL), 19(4/5/6), 381-395. https://doi.org/10.1504/IJCEELL.2009.028834

\section{DOI:}

10.1504/IJCEELL.2009.028834

Document status and date:

Published: 01/10/2009

Document Version:

Peer reviewed version

\section{Document license:}

CC BY-NC-ND

Please check the document version of this publication:

- A submitted manuscript is the version of the article upon submission and before peer-review. There can be important differences between the submitted version and the official published version of record. People interested in the research are advised to contact the author for the final version of the publication, or visit the DOI to the publisher's website.

- The final author version and the galley proof are versions of the publication after peer review.

- The final published version features the final layout of the paper including the volume, issue and page numbers.

Link to publication

\section{General rights}

Copyright and moral rights for the publications made accessible in the public portal are retained by the authors and/or other copyright owners and it is a condition of accessing publications that users recognise and abide by the legal requirements associated with these rights.

- Users may download and print one copy of any publication from the public portal for the purpose of private study or research.

- You may not further distribute the material or use it for any profit-making activity or commercial gain

- You may freely distribute the URL identifying the publication in the public portal.

If the publication is distributed under the terms of Article 25fa of the Dutch Copyright Act, indicated by the "Taverne" license above, please follow below link for the End User Agreement:

https://www.ou.nl/taverne-agreement

Take down policy

If you believe that this document breaches copyright please contact us at:

pure-support@ou.nl

providing details and we will investigate your claim.

Downloaded from https://research.ou.nl/ on date: 26 Apr. 2023 


\title{
Effect of adaptive learning style scenarios on learning achievements
}

\author{
Danail Bozhilov ${ }^{1}$, Krassen Stefanov ${ }^{1}$, Slavi Stoyanov ${ }^{2}$ \\ ${ }^{1}$ St. Kl. Ohridski University of Sofia, \\ 5, James Bourchier Blvd, 1164 Sofia, Bulgaria \\ danail@gmail.com, krassen@fmi.uni-sofia.bg \\ ${ }^{2}$ Centre for Learning Sciences and Technologies, \\ Open University of The Netherlands \\ Slavi.Stoyanov@ou.nl
}

\begin{abstract}
The study compares three adaptive learning style scenarios, namely matching, compensating and monitoring. Matching and compensating scenarios operate on a design-time mode, while monitoring applies a run-time adaptation mode. In addition, the study investigates the role of pre-assessment and embedded adaptation controls. To measure the effectiveness of different adaptive scenarios, a software application serving as a test-bed. was developed. An experimental study indicated that the monitoring adaptation led to higher learning achievements when compared to matching and compensating adaptation, although no significant effect was found.
\end{abstract}

Keywords: adaptive learning, adaptive software applications, learning style

\section{Adaptive software applications for educational purposes}

The development of adaptive software applications for educational purposes has been dominated by instructional design solutions predominantly based upon level of knowledge (Corbalán-Pérez, Kester, \& van Merriënboer, 2006; Kicken, Brand-Gruwel \& van Merriënboer, 2008; Merrill, 2002; Oughton \& Reed, 2000; Steele, 2003; Wisberg, 2003). Since recently, however, the adaptive software application paradigm has been experiencing a shift of interest to learning style as another important cognitive construct to take into account (Brown, Cristea, Stewart, \& Brailsford, 2005; Gilbert \& Han 1999; Merrill, 2002; Papanikolaou, Grigoriadou, Kornilakis, \& Magoulas, 2003). Research on learning style has a relatively long standing tradition (see Jonassen \& Grabowski, 1993; Riding \& Reiner, 1997), but it has produced some contradictory findings, which need explanation in order to inform the design and development of adaptive software applications. The contrasting results can be defined as: (a) predictive effects of style on achievements (Martinsen, 1995; Martinsen \& Kaufmann, 1999; Oughton \& Reed, 2000) vs no predictive effects of style on achievements (Ayersman \& von Minden, 1995; Kirton, 2003; Meneely \& Portillo, 2005; Kommers et al., 2008; Steele, 2003; Stoyanov, 2001; Stoyanov
\& Kirschner, 2007); and (b) interaction effects between instructional methods and styles on achievements (Martinsen \& Kaufmann, 1999) vs no interaction effect between treatment and style (Stoyanov, 2001; Kommers et al., 2008; Stoyanov \& Kirschner, 2007). There are two groups of reasons that account for the contradiction in these research outcomes. The first one is related to the definition and conceptual operationalization of learning style as a cognitive construct. The second one is related to the definition and theoretical background of adaptive instruction.

\subsection{Conceptual operationalization of learning style}

Learning style can be defined as a stable pattern of individual cognitive functions and traits that determine the preferred way of approaching instructional stimuli.. Relatively recent conducted studies (Kirton, 2003; Kommers et al., 2008), within the contemporary learning style paradigm, have empirically validated a number of theoretical assumptions that can be used as a basis for the design and development of adaptive software applications. These assumptions are as follows:

1. A clear distinction should be made between style (in what way) and level (how much) classes cognitive constructs. Some examples of level types of constructs are abilities, knowledge, and competence. 
Level and style measures, if pure, correlate not at all. Learning style is non-pejorative construct. For example, reflector learning style is not better than activist, they are just different. Some instructional situations however could favor more a particular style than other.

2. Style has to be distinguished from process constructs (learning process or problem solving process) as well. At each stage of a process different styles can be identified, so can levels. Each stage can be executed at levels ranging from low to high and learning style ranging, from, let us say, activist to reflector.

3. Style and behavior could not necessary be in accord, or there could be a 'cognitive gap' between preferred behavior and observable behavior. People may happen to behave outside their prefer way of doing, a situation in which they apply the cognitive mechanism of coping behavior. They could be convinced or forced to learn in a way that is different from their learning style, as this way is considered to be more effective or socially desirable. People are capable to cope with such sort of situations but it is always at the expense of more efforts, energy and time. Flexibility of learning requires not only learning strategies that conform to a preferred style, but also a shift to less favorite learning styles, that are more effective in a particular situation.

4. A learning strategy, method or technique, can be learned to increase the level of performance directly, or to make more effective use of the available style as stimulating its strengths and compensating for its weakness.

5. Issues related to relevant operationalizion of learning style has affected the construction of measurement instruments for learning style. Many of them have low validity and reliability indicators (see Kolb's Learning Style Inventory -LSI, 1976; Felder-Silverman Index of Learning Styles - FS-ILS, 1988; Vermunt (1996).

\subsection{Adaptive instruction based on learning style}

Any attempt for an effective adaptive instructional design approach based upon learning style should take into account the advancement of the learning style theory, as discussed in the previous section. Adaptation has been associated with a purposeful effort for accommodating individual differences in learner characteristics for designing effective instruction (Jonasssen \& Grabowski, 1993). Several instructional design adaptive approaches to accommodate learning style have been developed. Preferential adaptation (Jonassen \& Grabowski, 1993; Stoyanov, 2001) implies that the instructional decisions take into account the strengths of a particular learning style. Compensation adaptation (Clark, 1983; Jonassen \& Grabowski, 1993; Salomon, 1979) takes into account the weaknesses of a particular style to compensate for them.

Matching and compensation adaptation may include a pre-assessment (Jonassen \& Grabowski, 1993; Stoyanov, 2001; Valley 1995) or an embedded adaptive control (Stoyanov, 2001; Valley 1995). Pre-assessment adaptation specifies learning paths of learners on the basis of filling out some instruments such as check-lists, tests, inventories, or questionnaires. Embedded adaptation accommodates learning styles through a particular way of structuring learning content: background information, examples, procedures and practice requirements. Learner's preferences can be implicitly identified through selecting the type and order of these instructional stimuli.

Pre-assessment and embedded adaptive controls can be part of either design-time adaptation (Gilbert \& Han 1999; Stoyanov, 2001) or runtime adaptation modes (Brown, Cristea, Stewart, \& Brailsford, 2005, Van Merriënboer \& Luursema, 1996, cited in Van Merriënboer, Clark, \& Crock, 2002) ). In the former mode all actions are predefined in advance. In the later mode, adaptation is realized through monitoring and tracking of students' behaviour using the inputs from either a pre-assessment or an embedded type of adaptive control. The technological development of adaptive instructional scenarios depends heavily on their conceptual design, that is how well they implement learning style adaptive models, modes and controls.

\subsection{Technological implementations of adaptive approaches on learning styles}

The most productive theoretical frameworks in which many projects in developing adaptive educational applications have been realized are 
Intelligent Tutoring Systems, Adaptive Educational Hypermedia, and Adaptive Educational Web-Based Systems (Brown at al, 2005; Papanicolaou et al., 2003; Specht \& Kravcik, 2006). These frameworks represent actually one paradigm (Intelligent Educational Systems), which is built upon a common conceptual background that includes domain knowledge, expert model, student model, pedagogical model, and communication model. The most considerable contribution of this paradigm, perhaps, is the development of techniques for run-time adaptation. The systems that have been developed within the Intelligent Educational Systems paradigm made considerable progress in refining the properties of user models and promoting more advanced instructional techniques, but some important issues still remain to be addressed. The problems related to the definition of adaptation and conceptualization of learning style can be identified in the development of adaptive software applications within this paradigm. In some of the applications no distinction is made between knowledge, which is a level type of cognitive construct, and learning style, which is a preference type of cognitive construct (Brown at al., 2005). In other attempts, no difference is made between learning style and instructional strategy (Gilber \& Han, 1999). Most of the systems implemented measurement instruments that had low validity and reliability indicators (see for example Brown et al., 2005; Papanicolaou et al., 2004). The current Adaptive Educational Hypermedia (AEH) projects tend to connect the instructional strategy to the learner model, but it is not always explicitly stated which specific instructional approach is used (Brown et al., 2005). When the instructional approach is specified, in the most of the cases, it does not reflect the current trends in modern instructional design theory and practice (see Papanicolaou et al., 2004). Sometimes the discussion on design approaches, based on learning styles, has been replaced by a discussion on learning style classifications (Brown at al., 2005). When the design approach for adaptation is explicitly referred to, typically it is the preferential type of adaptation, based on pre-assessment (Papanicolaou et al., 2004).

This paper is aimed at comparing matching, compensating and monitoring. adaptive scenarios based on learning style. Matching and compensating scenarios operate on a design- time mode, while monitoring applies a run-time adaptation mode. In addition, within the adaptive scenarios, the role of pre-assessment and embedded adaptation controls is a subject of investigation. The study explores the following research questions:

1. What is the effect of matching, compensating, and monitoring adaptive scenarios on complex learning?

2. Is there any effect of learning styles on learning achievements in complex learning situations?

To provide answers to these research questions, we developed a software application, which implements different adaptive scenarios including adaptive modes and controls. The tool is a test-bed for measuring the effectiveness of the adaptive scenarios.

\section{Functionality and architecture of the tool}

\section{$2.1 \quad$ Features}

The most important features of the tool are as follows:

1. Automatic students allocation to an experimental group, realized as both providing support for an automatic assignment of students based on their learning styles questionnaire results and accounting for the registration time in order to achieve equal split of the users with the same learning style (Activist or Reflector) among the three predefined learning paths

2. Run-time adaptation, that is providing support for run-time adaptation based on embedded adaptation control.

\subsubsection{Automatic student allocation to an experimental group}

In order to equally split the students having the same learning style across the experimental groups, there is a check for the current state of distribution as the student is allocated to the experimental group where the lowest number of students with the same learning style is. As there are three groups, it is clear, in one third of the times, which group has the lowest number of students with the same learning style, and in two third of the times there is a random selection between the groups where this number is equal. This algorithm allows equal split of the same learning style between the experimental 
groups, ensuring a distribution of an equal number of students in the three groups.

\subsubsection{Run-time adaptation}

The run-time adaptation is applied to one of the experimental groups, called Monitor (see section Method for more details). The design is based on tracking the student click stream and matching his/her behavior pattern to a predefined signature scores.

\section{***INSERT FIGURE 1 ABOUT HERE***}

In this way the student already has a current score, which determines whether s/he is i.e. more Activist or Reflector and the system shows accordingly the learning content designed for this particular learning style.

There are 15 signatures possible, built upon a combination of the three different types of learning support, namely, theory, procedures and examples. The signature is formed based on the sequence of these types of supports, which the student visits when studying a particular learning content. The sum of all signatures for all learning content modules defines the student's current score and determines which content the system shows next. The score scale of the signatures is between -5 and 5 where the negative direction indicates the range of Reflector style and the positive direction indicates the range of Activist style. It means that a student with positive current score is assigned to the Activist content and a student with a negative current score is assigned to the Reflector content.

3. The time spent on a page is also tracked but it is not reported here. The plan is to enhance the run-time adaptation in the next release of the tool in order to build a more sophisticated scoring algorithm.

\subsection{Architecture}

The tool is a web-based application having two tiers and utilizing Microsoft technologies:

- Database server - MS SQL Server

- Web server - Internet Information Server
- Programming Technology - Active Server Pages 3.0

o Server Side Script - VBScript

o Client Side Script - JavaScript

o XHTML, CSS, etc.

\section{$3.2 \quad$ Typical usage scenarios}

The order of logical arrangements of the tool when used by a student is as follows:

1. Register

2. Login

3. Read the tool and experiment overview

4. Fill in the Learning Styles Questionnaire

5. Learn the Case presented

6. Fill the Achievement Test for the Case

7. Submit any Assignments required

Figure 1 illustrates the implementation of the learning style questionnaire and the learning achievement test.

***INSERT FIGURE 2 ABOUT HERE***

The student can also provide feedback for the tool usability at any time.

The main logical arrangement of the tool during the usage by the administrator is as follows:

1. Login

2. Create Cases

3. Create Methods for each Case

4. Create Techniques for each Method

5. Populate the content for each Technique

a. Activist Theory

b. Activist Example

c. Activist Procedure

d. Reflector Theory

e. Reflector Example

f. Reflector Procedure

The administrator can also manage student accounts, review their feedback, learning styles questionnaire results and assignments submitted, and edit the tool and experiment overview content.

\subsection{Research Design}

The research design of the study draws upon two research perspectives: (a) design research (Brown, 1992; Collins, Joseph, \& Bielaczyc, 
2004) or process research (Richey \& Nelson, 1996) and (b) experimental research. Process research (design research) investigates the whole or the part of the process of design, development, and evaluation of a tool for educational or training purposes. A process research project addresses a context-specific problem situation to determine the characteristics of what is going to be developed along with attempting to understand and improve the design process and the designer problem solving by developing new tools and techniques.

Regarding the experimental research perspective, the study applies factorial experimental design. The independent variables are (a) adaptive instructional scenarios with three levels: matching, compensating and monitoring, on the one hand; and (b) learning style, on the other hand. The dependent variable is learning achievement of students. The two lines of research, (design) process research and experimental study, are complimentary to each other. The software application creates conditions for the experimental research. The results of the experimental study will be used for improving the software.

\subsection{Participants and procedure}

All the students following a master degree at a Faculty of Computer Science were invited to take part in the study. 216 students registered to the system. Of them, 152 filled out the learning style questionnaire and 49 did the learning achievement test. Only the participants who did the test are included in the analysis of this study. The participants had to study the software engineering technique called Writing Persona in the context of the case of designing and developing a faculty web portal. The students were randomly assigned to three groups. The learning content to study was the same for the three groups but it was structured in a different way.

The following heuristics have been used for structuring the learning content.

If the goal is to build a learning environment for the activist learning style, then involve the learner in a role-playing confronting her/him with a real life case (scenario, vignette) that has to be resolved. Describe the cast and the story.

If the goal is to support the learning experience of the activist learning style, then provide him/her with some heuristics for the systematic problem solving approach(s) to be applied to the case.

If the goal is to compensate for the weaknesses of the activist learning style, then present guided problems (modelling examples), "war" stories (work-out examples) and overview (theoretical models), preferably in this order.

If the goal is to support the reflector learning style, then present her/him with work-out examples, modelling examples and theoretical models, preferably in this order.

If the goal is to compensate for the weakness of the reflector learning style, then describe the real life context of the tasks, provide systematic problem solving approach(s), and ask for applying it on learning tasks.

One of the groups of students studied the learning content structured to match the preferences of the activist learning style. This learning track confronted the participants with a problem situation (designing a web portal) and involved them in a sort of role-playing. The main supportive activity was providing guidelines and procedures. There were also guided problems and war stories, which were secondary supportive activities and were used as illustrations for the guidelines and procedures. A second supportive activity was a short theoretical introduction, which was provided at the beginning of the study. This learning path included in addition alternative guidelines, procedures, techniques and theoretical models.

Another group of students followed a learning track where the primary supportive activities were examples (work-out example and demonstrations). The secondary supportive activities were (a) procedures, guidelines and techniques; and (b) an overview of theoretical models. The participants assigned to this group were asked to provide a solution to a project scenario, which described the task of designing a web portal.

For the third group, the different types of instructional support such as theoretical models, examples, procedures, and guidelines, were available to learners for a selection. Depending on the selection made, the system offered consequently particular learning support (procedure, guidelines, examples, and theoretical models) according to the run-time adaption rules.

The students who accepted the invitation to take part in the study were instructed to register to the system. Once registered they got an access 
to a learning style questionnaire to be filled out. After that the system randomly assigned the participants to one of the three learning tracks as described. The learning content, structured to match the activist learning style, represented a preferential condition for the activists and a compensation condition for the reflectors. Similarly, the learning track designed to meet the needs of the reflector learning style was a preferential condition for reflectors and a compensation condition for the activists. The learning content structured for the activist and reflector learning styles operationalises the idea of design-time adaption based on preassessment adaptive control. The third group worked with a framework implementing the idea of run-time adaption based on embedded adaption control. The participants in the three groups followed the content in their own pace and at the end took an achievement test. The system provided opportunity and students were in addition encouraged to express their opinions on the content, adaptive approaches applied and the usability of the system.

\subsection{Measurement Instruments}

Two types of measurement instruments were used in this study: an achievement test and a learning style questionnaire.

The achievement test included 10 items to measure the level of knowledge and skills on the technique Writing Persona. The test applied a context-dependent multiple-choice-multipleanswer format (testlets) with a vignette attached to some of the items. The reliability of the test reached a relatively high Cronbach alpha value (0.89).

The second measurement instrument was a revised version of the Honey-Mumford Learning Style Questionnaire (LSQ, 1992) for defining learning styles (De Ciantis \& Kirton, 1996). The original LSQ has been widely applied, but some recent factor-analytical studies showed that it did not produce stable psychometrical performance (see De Siantis \& Kirton, 1996). The four learning styles (Reflector, Theorist, Pragmatist, and Activist), which should be independent measures, actually form two orthogonal dimensions, each presenting a bipolar scale: Activist-Reflector and Theorist-Pragmatist (De Ciantis \& Kirton, 1996).

As a result De Ciantis and Kirton created a new 45-items scale (.90 alpha). The Activist-
Reflector scale is a pure 'style' type scale, which is appropriate for the purposes of the current study. The Theorist-Pragmatist scale seems to be problematic and unreliable and would not substantially contribute to the design blueprint and the measurement of learning styles. The modified LSQ was used for a first time. We hoped not only to reliably identify learning styles but also gradually to collect critical mass of data to validate the instrument and create norms.

\subsection{Data Analysis and Results}

The Levene test of homogeneity identified no violation of the analysis of variance's assumption. The variance in the learning achievement test across the three groups was equal $[\mathrm{F}(5 ; 43)=1.4,, \mathrm{p}=.245]$.

A two-way between-groups analysis of variance (ANOVA) was conducted to explore the effect of the three adaptive scenarios, Preferential adaptation, Compensation adaptation and Monitoring, on learning achievements of the students. There was not a statistically significant main effect for groups working under different adaptive scenarios $[\mathrm{F}(2,43)=$ $.225, \mathrm{p}=.800]$. The mean score of the Monitor group $(M=5.2)$ was higher than those of the Preferential adaptation group $(\mathrm{M}=4.3)$ and the Compensation adaptation group $(\mathrm{M}=4.5)$. Table 1 presents mean figures and standard deviations for adaptive scenarios and learning styles.

\section{***INSERT TABLE1 ABOUT HERE***}

The main effect for learning style $[\mathrm{F}(1,43)=$ $.135, \mathrm{p}=.715]$ and interaction effect between adaptive scenarios and learning style $[\mathrm{F}(2,43)$ $=1.168, \mathrm{p}=.321] \mathrm{did}$ not reach statistical significance. Figure 3 visualises the interaction pattern of adaptive scenarios and styles.

\section{***INSERT FIGURE 3 ABOUT HERE***}

\section{Discussion}

Although no significant difference among the three adaptive scenarios was found, the Monitor group demonstrated higher results than the Preferential and Compensation scenarios. The students assigned to the Monitor scenario could select the types of resources they prefer (either guidelines, procedures and techniques, or 
examples and demonstrations, or theoretical models). Based on learners' selection, the system suggests the next learning activity and resources. The suggestions are based on preferential matching, that is supporting the strengths of a particular style, but there are also hints as how to overcome the weaknesses of this learning style. The Monitor group implements the idea of embedded and implicit identification of learning style and it combines features of both the preferential and compensation adaption. The results of the study encourage further investigation of this approach for learning adaptation.

As it was expected, the study yielded no significant difference between learning styles. Learning style is about preferences of people, not about their level of knowledge, skills, or cognitive ability. People with a different level of capacity can be found within samples of different learning styles. In addition, even when put in a not preferable condition, people on the same level are capable to do what is required from them as they switch on the cognitive mechanism of coping behaviour (Kirton, 2003). Related to this, the current study brings some interesting ideas, worth to be further investigated. It seems that students with reflector learning style are more comfortable with the preferential adaptive instructional arrangements, while students with activist learning style deal better with the compensation adaption scenario. Reflectors showed a decrease of their learning achievements within the Monitor adaptive approach, while activists demonstrated an increase in their test scores (see Figure 3). Both style perform closely within the Monitor adaptive scenario.

The study sheds light on some issues related to learning adaption and its technological implementation as it also "open the door" for future research and development. The results could be seen as a contribution to at least three aspects of the research conducted within the Adaptive Educational Web-Based Systems paradigm. First it is a refinement of learner model, specifically its learning style part. Second, it is an improvement of the pedagogical model with the adaptive models, modes and controls tested in this study. Third, it is the design of a new interaction mode between learner model, pedagogical model and the content model.

The study, however, has some flaws from research methodology point of view. It would be useful to report on the effect of the adaptation scenario not only on learning achievements of students but also on their attitudes. How do students like adaptation approaches, and does learning style produce any difference among students in this respect? The satisfaction was included as a variable in the initial research plan, but we are not ready to report on it because we are still collecting data. The system also technically affords users to comment on different issue - content, adaptation approach, usability, and interface.

The sample of students is skewed toward the activist learning style, which means that activists and reflectors are not equally distributed across the three study groups.

Although the achievement test was equal for the three groups, and the Levene test indicated equally distributed variations of the test results, we suspect a 'floor' effect, which could explain the relatively low mean of the scores in the three groups.

\section{Conclusions}

This exploratory study was aimed at identifying some issues related to designing adaptive learning scenarios accommodating learning styles. The results will be used for attuning the research design and improving the software application, which we developed for the purposes of this study. We thought that building a prototype was the best way of operationalising theoretical constructs such as learning style, adaptive learning scenarios, modes and controls. The study confirmed our assumptions regarding learning style as a cognitive construct of preference type. Coping behaviour as a cognitive phenomenon provided a good explanation for the lack of difference in the performance of people with different learning style as well. The Monitor adaptive scenario, implementing the embedded adaptation control and run-time adaptation mode, seems a promising idea and need further investigations.

\section{References}

[1] Atkinson, G. (1988). Reliability of the learning style inventory. Psychological Reports, 62, 755-758.

[2] Brown, A. (1992). Design experiments: theoretical and methodological challenges in creating complex interventions in 
classroom settings. The Journal of the Learning Sciences, 2(2), 141-178.

[3] Brown, E., Cristea, A., Stewart, C., \& Brailsford, T. (2005). Patterns in authoring of adaptive educational hypermedia: a taxonomy of learning styles. Educational Technology \& Society, 8(3), 77-90.

[4] Clark, R. (1983). Reconsidering research on learning from media. Review of Educational Research, 53, 445-459.

[5] Collins, A., Joseph, D., \& Bielaczyc (2004). Design research: theoretical and methodological issues. The Journal of the Learning Sciences, 13 (1), 15-42.

[6] Corbalán-Pérez, G.,Kester, L., \& van Merriënboer, J. (2006). Towards a personalized task selection model with shared instructional control. Instructional Science, 34, 399-422.

[7] De Ciantis, S. \& Kirton, M. (1996). A psychometric reexamination of Kolb's experiental learning cycle construct: a separation of level, style, and process. Educational and Psychological Measurement, 56 (5), 809-820.

[8] Felder, R., \& Silverman, L. (1988). Learning and teaching styles in engineering education. Engineering Education, 78 (7), 1988, 674-681.

[9] Gilbert, J., \& Han, C. (1999). Adapting instruction in searching of a 'significant difference'. Journal of Network and Computer Applications, 22, 149-160.

[10] Honey, P., \&. Mumford, A. (1992) The Manual of learning styles. Maidenhead, Berkshire: Published and Distributed by Peter Honey.

[11] Jonassen, D., \& Grabowski, B. (1993). Handbook of individual differences, learning and instruction. Hillsdale, NJ: LEA.

[12] Kicken, W., Brand-Gruwel, S., \& Jeroen J.G. van Merriënboer (2008). Scaffolding advice on task selection: a safe path toward self-directed learning in ondemand education. Journal of Vocational Education and Training, 60 (3), 223-239.

[13] Kirton, M. (2003). Adaption - Innovation in the context of diversity and change. London: Routledge.

[14] Kommers, P., Stoyanov, S., Mileva, N., \& Martínez Mediano, K. (2008). The effect of adaptive performance support system on learning achievements of students. International Journal of Continuing Engineering Education and Lifelong Learning, 18 (3), 351-365.

[15] Marschall, J. \& Merritt, S. (1986). Reliability and construct validity of alternate forms of the Learning Style Inventory. Educational and Psychological Measurement, 45, 931-937.

[16] Martinsen, O. (1995). Cognitive styles and experience in solving insight problems: replication and extension. Creativity Research Journal, 8, 291-298.

[17] Martinsen, O., \& Kaufmann, G. (1999). Cognitive style and creativity. In $\mathrm{M}$. Runco \& S. Pritsker (Eds.), Encyclopedia of creativity, V. 1 (pp. 273-282). New York: Academic Press.

[18] Meneely, J., \& Portillo, M. (2005). The adaptable mind in design: relating personality, cognitive style, and creative performance. Creativity Research Journal, 8, 291-298.

[19] Merrill, M. D. (2002). Instructional strategies and learning styles: Which takes precedence?. In R.A. Reiser, \& J.V. Dempsey, (Eds.). Trends and issues in instructional technology (pp. 99-106). Columbus, OH: Prentice Hall.

[20] Myers, I.B., Myers, P. B. (1995). Gifts differing. Understanding personality types. Palo Alto, CA: Davies-Black Publishing.

[21] Oughton, J. M., \& Reed, W. M. (2000). The effect of hypermedia knowledge and learning styles on student-centered concept maps about hypermedia. Journal of research on computing in education, 32 (3), $366-383$.

[22] Papanikolaou, K., Grigoriadou, M., Kornilakis, H., \& Magoulas,, G. (2003). Personalizing the interaction in a webbased educational hypermedia system: the case of ISPIRE. User Modelling and UserAdapted Interaction, 13, 213-267

[23] Riding \& Reiner, (1997). Toward categorization of cognitive styles and learning styles. An International Journal of Experimental Educational Psychology (Double special issue), V. 17, 1 \& 2 (March and June), 1997, 5-27.

[24] Salomon, G. (1979). Interaction of media, cognition and learning. Mahwah, NJ: LEA. 
[25] Smith, D., \& Kolb, D. (1986). Manual of Learning Style Inventory (LSI-II). Cambridge.

[26] Specht, M. \& Kravcik, M. (2006). Authoring of learning objects in context. International Journal on E-Learning. 5 (1), 25-33

[27] Steele, D. (2003). The influence of cognitive style on insightful problem solving. Unpublished MSc thesis. Buffalo State College, State University of New York.

[28] Stoyanov, S. (2001). Mapping in the educational and training design. Doctoral dissertation, University of Twente, Enschede, The Netherlands: Print Partners Ipskamp.

[29] Stoyanov, S., \& Kirschner, P. (2007). Effect of problem solving support and cognitive style on idea generation: Implications for Technology-EnhancedLearning. Journal of Research on Technology of Education, 40 (1), 49-63.

[30] Valley, K (1995). Learning styles and courseware design. Advance Learning Technology Journal (ALT-J), V. 5, 2, 4351.

[31] Van Merriënboer, J., Clark, R., \& de Croock, M. (2002). Blueprints for complex learning: the 4C/ID model. Educational Technology, Research \& Development, 50(2), 39-64.

[32] Van Merriënboer, J., \& Kirschner, P. (2007). Ten steps to complex learning. A systematic approach to four-component instructional design. Mahwah, New Jersey: Lawrence Erlbaum Associates.

[33] Vermunt, J. D. (1996). Metacognitive, cognitive, and affective aspects of learning styles and strategies: a phenomenographic analysis. Higher Education, 31, 25-50.

[34] Weisberg, R. (2003). Creativity and knowledge. In J. Davidson \& R. Sternberg (Eds.), The Psychology of problem solving (pp.226-250). New York: Cambridge University Press. 
Tables and Figures 
Table 1.

Mean figures and standard deviations for adaptive scenarios and learning style

\begin{tabular}{llll}
\hline Adaptive Scenarios & Learning Styles & M & SD \\
\hline \multirow{3}{*}{ Preferential } & Activist & 3.8 & 2.4 \\
& Reflector & 5.5 & 1.6 \\
& Total & 4.3 & 2.3 \\
\hline Compensation & Activist & 4.6 & 1.3 \\
& Reflector & 4 & 2.8 \\
& Total & 4.5 & 1.5 \\
\hline \multirow{2}{*}{ Monitor } & Activist & 5.2 & 1.7 \\
& Reflector & 5 & 0.1 \\
& Total & 5.2 & 1.6 \\
\hline
\end{tabular}

Note: Preferential scenario - 18 participants; Compensation scenario - 15; Monitor - 16. 


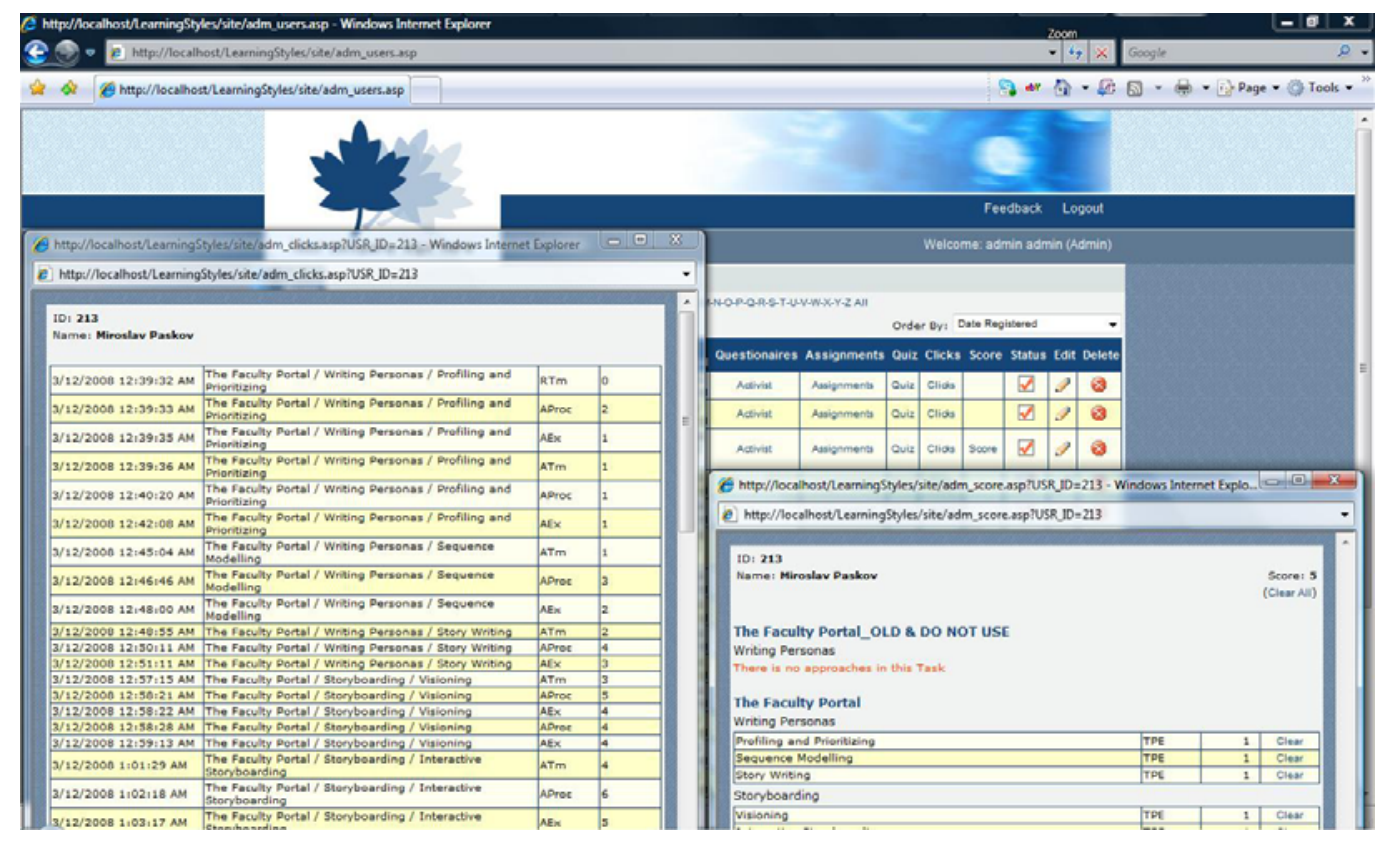

Figure 1. Learning Style Questionnaire and Achievement Test 


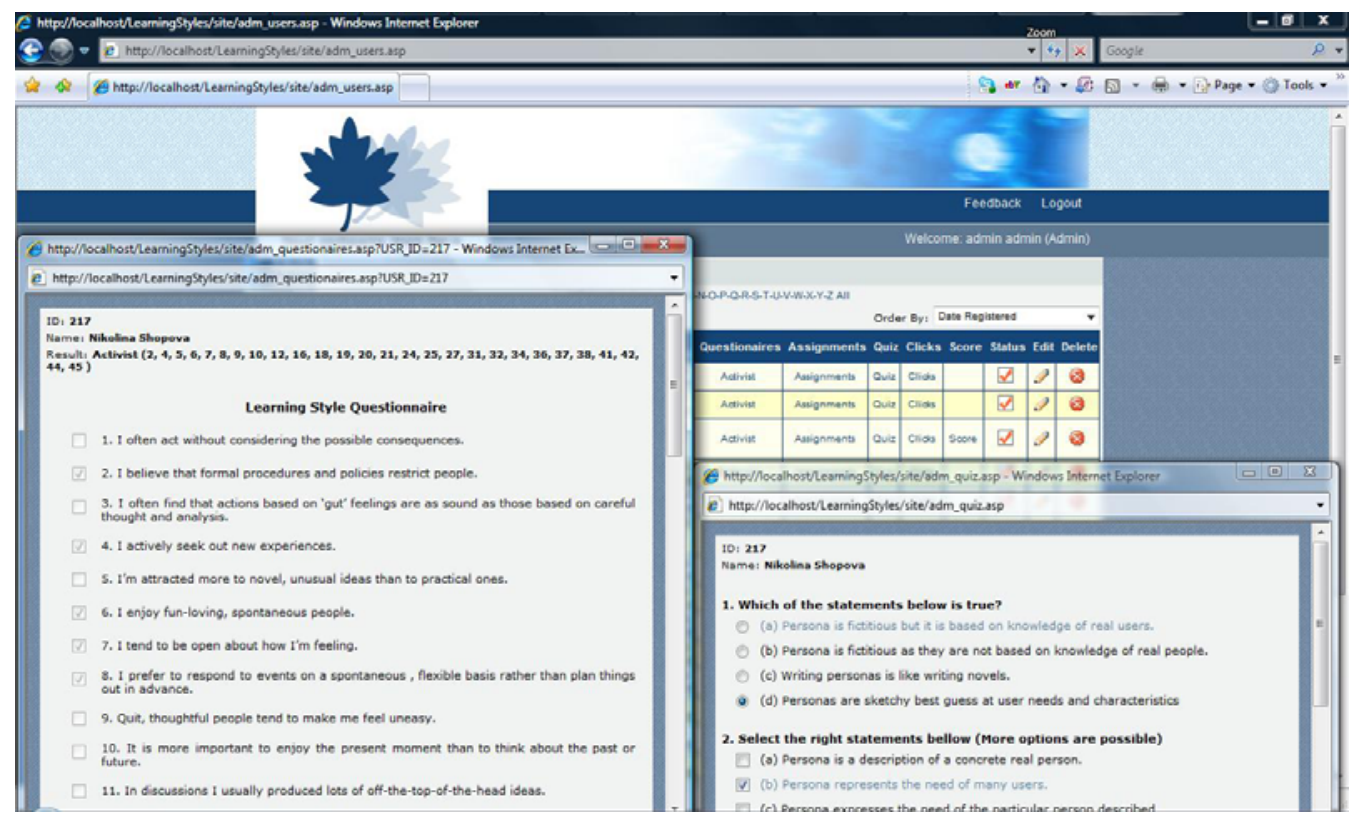

Figure 2. Student click stream and score 


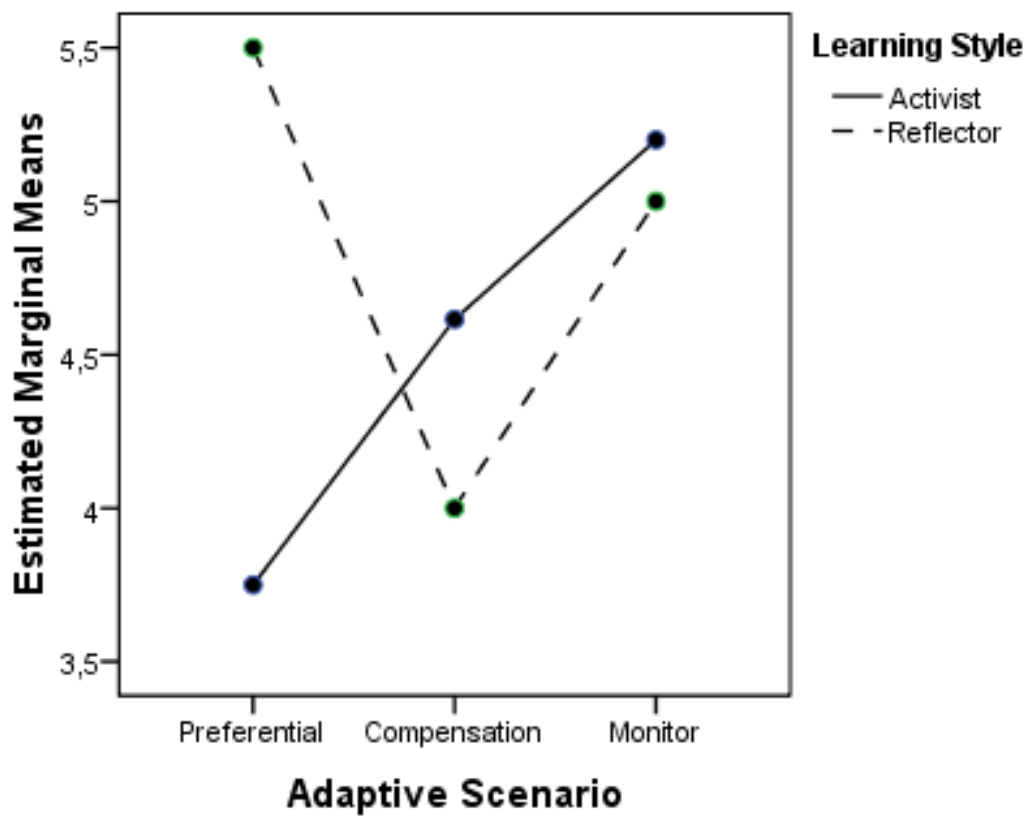

Figure 3. Interaction pattern of adaptive scenario and learning styles 